Communications in Physics, Vol.22, No. 1 (2012), pp. 65-73

\title{
PULSED ELECTRON DEPOSITION (PED) - A NOVEL TOOL FOR GROWTH OF THIN FILMS
}

\author{
NGO DINH SANG \\ National University of Civil Engineering \\ PHAM HONG QUANG AND DO QUANG NGOC \\ Hanoi University of Science, Vietnam National University
}

\begin{abstract}
Pulsed Electron Deposition (PED) is a novel technique that can be applied for growing high quality thin films. In this technique, we used an electron beam with a focused diameter of about $1 \mathrm{~mm}$, the energy up to $15 \mathrm{kV}$, the frequency of 1-10 $\mathrm{Hz}$, the pulse width of $100 \mathrm{~ns}$ and the total current of $1.5 \mathrm{kA}$ generated in a discharge system. A remarkable advantage of this technique is the low deviation in composition from bulk to film. By using the PED technique the transparent coducting $\mathrm{ZnO}$ and $\mathrm{Cu}(\mathrm{In} \mathrm{Ga}) \mathrm{Se}_{2}$ films were prepared. The effect of some deposition conditions on the properties of film has been examined and discussed. For $\mathrm{Cu}(\mathrm{In} G a) \mathrm{Se}_{2}$, the best film was obtained at the discharge voltage of $12 \mathrm{kV}$ and substrate temperature of $400^{\circ} \mathrm{C}$, while for $\mathrm{ZnO}$, the best film was grown at the oxygen pressure of $1.3 \mathrm{~Pa}$ and at $400^{\circ} \mathrm{C}$.
\end{abstract}

\section{INTRODUCTION}

Recently, Pulsed Electron Deposition (PED) has been attracting a great attention in thin film deposition [1-3]. This technique, also known as Channel-Spark Discharge and Pulsed Plasma Deposition, is based on a pulsed high power electron beam created in a low pressure gas discharge. The electron beams are characterized by short pulse widths $(\sim 100$ $\mathrm{ns})$, high energy density $\left(\sim 10 \mathrm{~J} / \mathrm{cm}^{2}\right)$, and are delivered to a target surface by relatively low-energy electrons $(\sim 10-20 \mathrm{keV})$, penetrating $\sim 1 \mathrm{~mm}$ into a target material, leading to a non-equilibrium heating that preserves the stoichiometric material transfer from the target to the substrate. PED shares some of the same advantages that characterize the well know technique, Pulsed Laser Deposition (PLD) such as easy control of film thickness, easy set-up, multicomponent film stoichiometry nearly identical to target material, and a relatively high deposition rate with low consumption of target materials. In addition, since electrons are charged particles, they interact very effectively via Coulomb interaction so that PED works for UV-transparent materials where PLD might fail. In fact, PED has been found to be useful for film deposition of complex materials such as superconductor, perovskite, oxides, and wide band gap semiconductor [4-6].

The structure of a CIGS based solar cell consists of several layers like the transparent conducting $\mathrm{ZnO}$ and the absorber $\mathrm{Cu}(\mathrm{InGa}) \mathrm{Se}_{2}$ layers. Growth of pure $\mathrm{ZnO}$ films by PED has been reported by Porter et al. [7], Nistor et al. [8], and Zhan et al [9]. And growth of CuInSe2 films by PED has been shown [10]. Andriesh et al. [11] also reported a two step deposition of $\mathrm{CuIn}_{1-x} \mathrm{Ga}_{x} \mathrm{Se}_{2}$ polycrystalline films with a "e-beam ablation" 
process followed by selenization at $500^{\circ} \mathrm{C}$. In this work, we show a PED system that has recently been set-up at Hanoi University of Science and its ability in growth of transparent conducting $\mathrm{ZnO}$ and $\mathrm{Cu}(\mathrm{InGa}) \mathrm{Se}_{2}$ films. Moreover, several issuers concerning the optimal growth conditions for getting good quality films have been shown.

\section{PULSED ELECTRON DEPOSITION TECHNIQUE AND EXPERIMENTAL DETAILS}

For the PED technique the channel spark system is used to produce a pulsed electron beam. The unit consists of a special type of hollow cathode, known as transient hollow cathode, a dielectric tube, which acts as an accelerator, and an air-filled spark-gap trigger tube for triggering the channel spark. For its operation the gas pressure in the system is maintained in the range of 0.7-2.7 Pa. By triggering the spark gap, constricted discharge is generated in the trigger tube, which ignites the transient hollow cathode. The electrons so generated form a beam and are accelerated through the dielectric tube. The general scheme of this process is shown in Fig. 1.

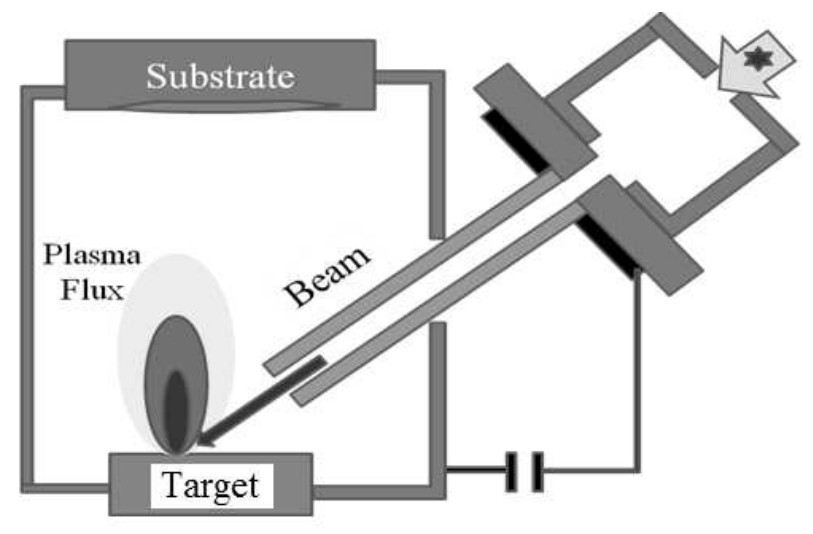

Fig. 1. General scheme of the PED process

In the beam, the mutual repulsion between the carriers is overcome by the magnetic self-field that keeps its trajectory self-focused and allows realization of the high current density of the beam [12]. The pulsed electron gun used in our experiments is a commercial source, PEBS-20 manufactured by Neocera, Inc. It has the following technical specifications: charging potential of $5-20 \mathrm{kV}$, beam energy of $0.2-0.8 \mathrm{~J}$, pulse duration of $100 \mathrm{~ns}$, maximum power density of $1.3 \times 10^{8} \mathrm{~W} / \mathrm{cm}^{2}$, beam cross section of about $6 \times 10^{-2} \mathrm{~cm}^{2}$, repetition rate of 1-10 Hz. In order to enhances the uniform erosion and reduces the "conic effect" on the surface of target, a target rastering feature was made by the movement of the target stage at the $\mathrm{X}-\mathrm{Y}$ plane about the central axis of the stage. Start angle, end angle, desired speed of rastering can be selected by the user using computer.

The CIGS films were deposited on glass substrate with the repetition rate of pulses maintained at $5 \mathrm{~Hz}$ and the argon pressure kept at $1 \mathrm{~Pa}$, two series of CIGS films were prepared. The deposition of the CIGS-1 films was carried out at room temperature and 
at four discharge voltages, viz., 8, 10, 12 and $14 \mathrm{kV}$. For the CIGS-2 films, the substrate temperature was ranged from room temperature to $600^{\circ} \mathrm{C}$ while the discharge voltage was kept at $12 \mathrm{kV}$. The target used in our work is a high purity commercial $\mathrm{Cu}\left(\mathrm{In}_{0.7} \mathrm{Ga}_{0.3}\right) \mathrm{Se}_{2}$ which has a diameter of 2 inch and a thickness of $3 \mathrm{~mm}$. All samples were deposited with 20,000 pulses.

$\mathrm{Al}$-doped $\mathrm{ZnO}(\mathrm{AZO})$ thin films were deposited on quartz substrates. During growing process, the discharge voltage and the pulse frequency were maintained at $14 \mathrm{kV}$ at 5 $\mathrm{Hz}$, respectively. We chose the optimal potential discharge voltage of $14 \mathrm{kV}$ as reported by Strikovski [13], with this voltage a maximal deposition rate can be obtained.. We also made two series of films; the series named AZO-1 was deposited at room temperature but at four pressures, viz., 0.7, 1.3, 2.0, $2.7 \mathrm{~Pa}$ of oxygen. The other series named AZO-2 was deposited at $1.0 \mathrm{~Pa}$ oxygen pressure but at the substrate temperatures ranged from $150^{\circ} \mathrm{C}$ to $600^{\circ} \mathrm{C}$. During deposition process, the pressure was maintained by controlling the balance between the rate of high vacuum pump and the flow of oxygen gas introduced into the chamber. The target used is a high purity commercial 2 wt $\% \mathrm{Al}_{2} \mathrm{O}_{3}$ doped $\mathrm{ZnO}$ target having a diameter of 2 inch and a thickness of $3 \mathrm{~mm}$. These samples were also deposited with 20,000 pulses.

The crystallinity of the films was checked by a Bruker-D5005 X-ray. Thickness of the films was determined by the stylus profiler (Detark-D150) and surface morphology was examined by SEM (Jeol-JSM5410LV). The optical properties were measured using UV-vis spectrophometer (UV-2450) in the wavelength range from 200 to $800 \mathrm{~nm}$. The electrical resistivity was determined by four probe technique at room temperature.

\section{RESULTS AND DISCUSSION}

\section{III.1. $\mathrm{Cu}(\mathrm{InGa}) \mathrm{Se}_{2}$ films}

The thickness of the CIGS-1 films was found to be 500, 650, 750 and $800 \mathrm{~nm}$ for the films grown at voltages of $8,10,12$ and $14 \mathrm{kV}$, respectively. This result can be expected from the fact that the discharge voltage is the main factor determining the number of material ions created by ablation. For the CIGS-2 films, the thickness decreases slightly with increasing substrate temperature, corresponding to the enhancement of the crystallinity which will be mentioned below.

Fig. 2 shows the SEM images of some typical samples. For the CIGS-1 films, particulates in the range from 50 to about $100 \mathrm{~nm}$ are present on the surface of the films, whatever the value of discharge voltage. However, the density and the size of the particulates are smaller in the films deposited at lower voltage. The origin of these particulates is a matter of discussion. They can be directly emitted by the target during electron beam ablation, or they can be formed in the gas phase, during the transport of species from the target to the substrate. It is interesting to note that the surface morphology of the films was improved as increasing the substrate temperature. The film growth at $600^{\circ} \mathrm{C}$ has isolated grains with uniform size and well-defined boundaries, indicating a very good crystalinity. We have made an attempt to determine the composition of the films by using EDS but the result is not reliable due to the influence of the glass substrate. 


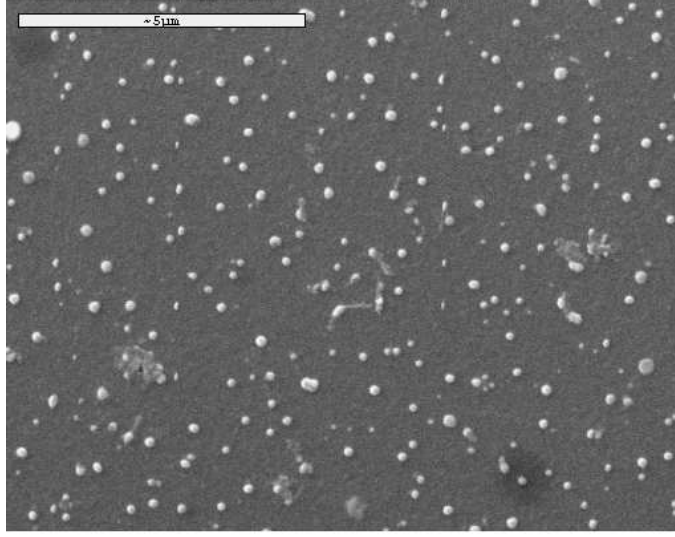

a)

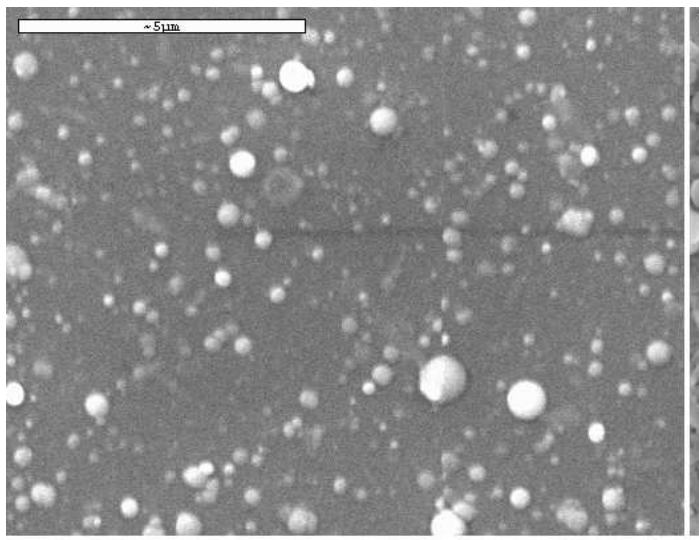

c)

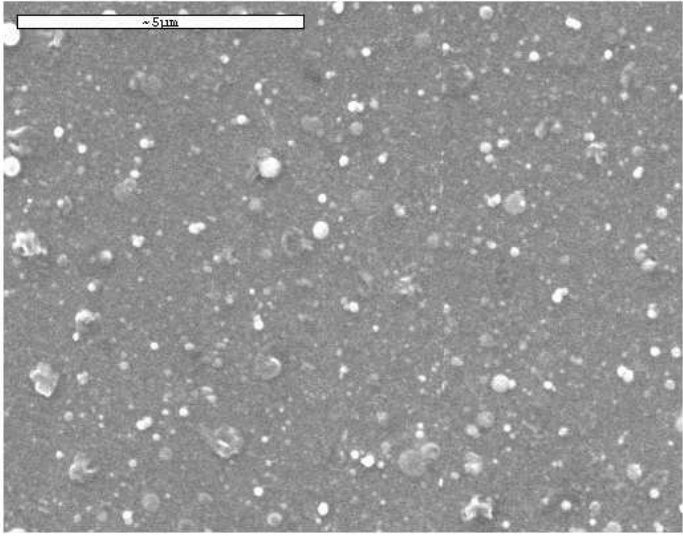

b)

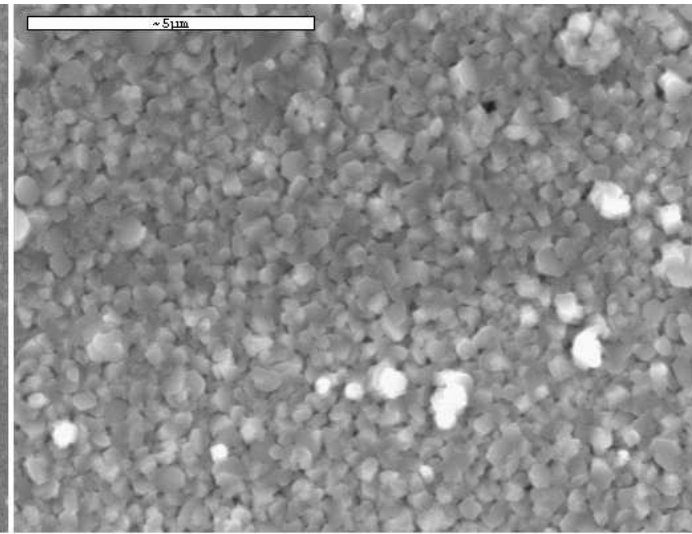

d)

Fig. 2. (a),(b),(c) SEM images of CIGS-1 films grown at 8, 12 and $14 \mathrm{kV}$, respectively and (d) SEM image of CIGS-2 film grown at $12 \mathrm{kV}$ and $600^{\circ} \mathrm{C}$

The XRD patterns of CIGS-1 and CIGS-2 films are shown in Fig. 3(a) and 3(b), respectively. We can see that all CIGS-1 films (i.e. the films grown at room temperature) have an amorphous structure. The (112) peaks of chalcopyrite structure are observed in the XRD patterns of the CIGS-2 films, indicating the enhancement of crystalinity. These observations are in accordance with the SEM images. The orientation of the (112) peak and the grain size estimated by the full width at half-maximum of the (112) peak increase with increasing the substrate temperature. It is worth to note that the preference orientation of (112) face is a necessary requirement of the CIGS absorber layer for a high performance CIGS thin film solar cell. The improvement of the crystallinity is due to as the increase of the substrate temperature.

The absorption spectra of the CIGS-1 films have a tail in the transparent range which may be caused by the poor crystallinity of the films. Except the case of film growth at $150^{\circ} \mathrm{C}$, the absorption spectra of the CIGS-2 films are typical for a direct 


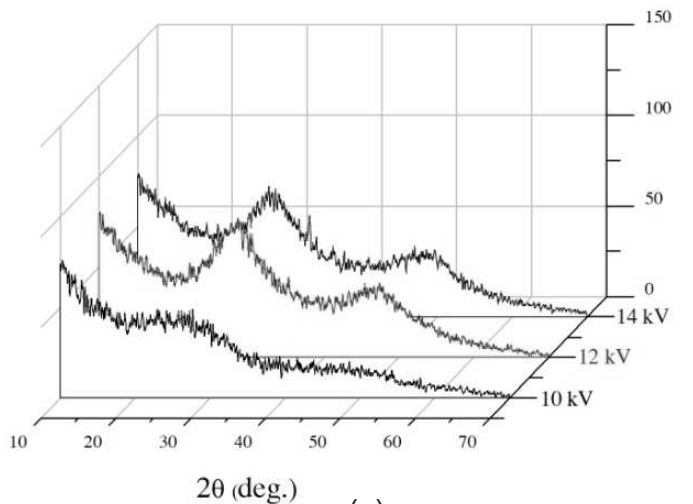

(a)

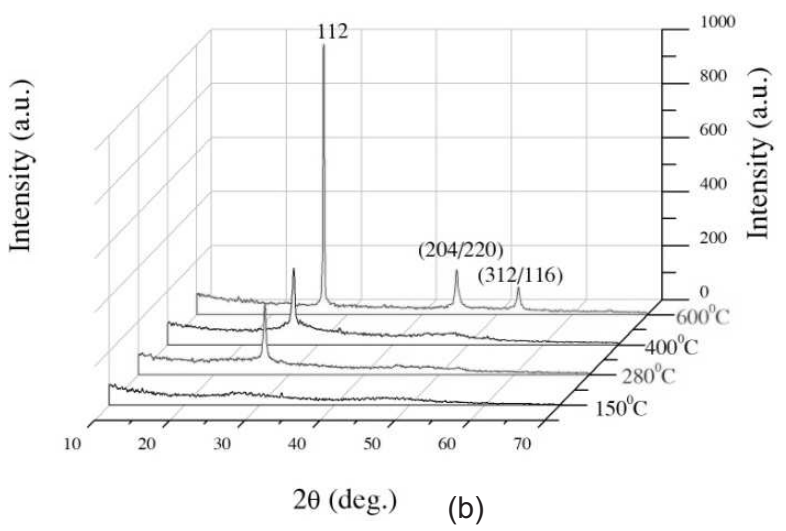

(b)

Fig. 3. The XRD patterns of (a) CIGS-1 films and (b) CIGS-2 films

band semiconductor which has a steep absorption edge. Fig. 4 shows the photon energy dependence of the square absorption coefficient for the films grown at $150^{\circ} \mathrm{C}, 280^{\circ} \mathrm{C}, 400$ ${ }^{\circ} \mathrm{C}$ and $600^{\circ} \mathrm{C}$. The band gap about $1.4 \mathrm{eV}$ was determined by extrapolating the linear portion of these curves. This value of band gap is in agreement with the expected value for a bulk $\mathrm{Cu}\left(\mathrm{In}_{0.7} \mathrm{Ga}_{0.3}\right) \mathrm{Se}_{2}$ sample [14]. It means that the stoichiometry of target materials is preserved in the film. It is very difficult to compare our results with those reported by Andriesh et al. [11] because their results were measured on the samples which have undergone the selenization process.

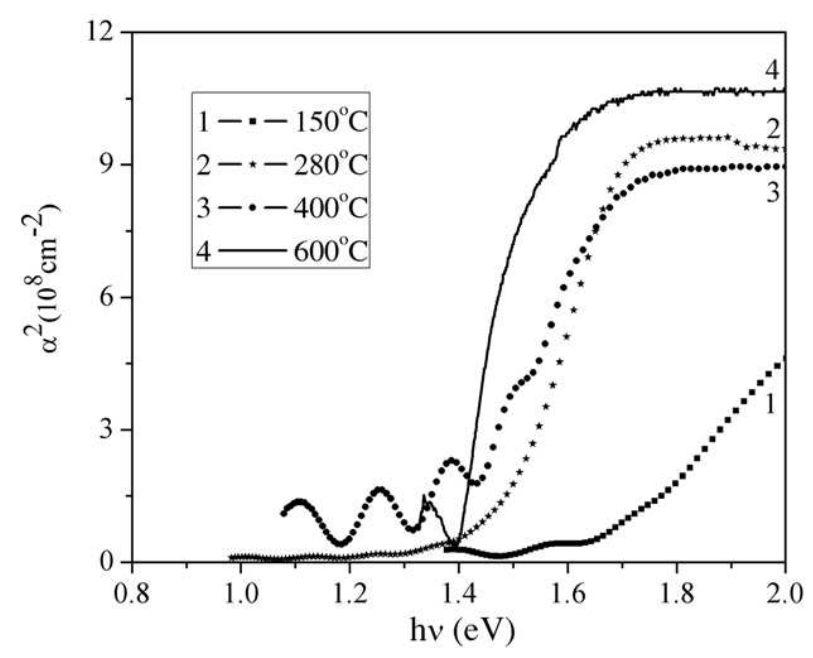

Fig. 4. The square of the absorption coefficient versus the photon energy curves for the CIGS-2 films 


\section{III.2. Al doped-ZnO}

The thickness of the $\mathrm{ZnO}$ films is strongly dependent on the oxygen pressure. The thickness of the AZO-1 films is 270, 250, 230 and $220 \mathrm{~nm}$ for the films grown at 0.7, 1.3, 2.0 and $2.7 \mathrm{~Pa}$ oxygen pressure, respectively. The thickness of the AZO-2 films is almost identical with the value of about $250 \mathrm{~nm}$. The decrease of the thickness with oxygen pressure can be can be attributed to the interaction between incoming ions in plasma flux and gas atoms, resulting in a decrease of current of ions arriving at the substrate. The SEM images of AZO (not shown) films are quite similar to those of CIGS films with the particals presenting on surface. Nistor et al also observed the similar problem [8] in growth of $\mathrm{ZnO}$ films and suggested the possibility to reduce it by careful optimization of the electron beam parameters in relation to the target materials.

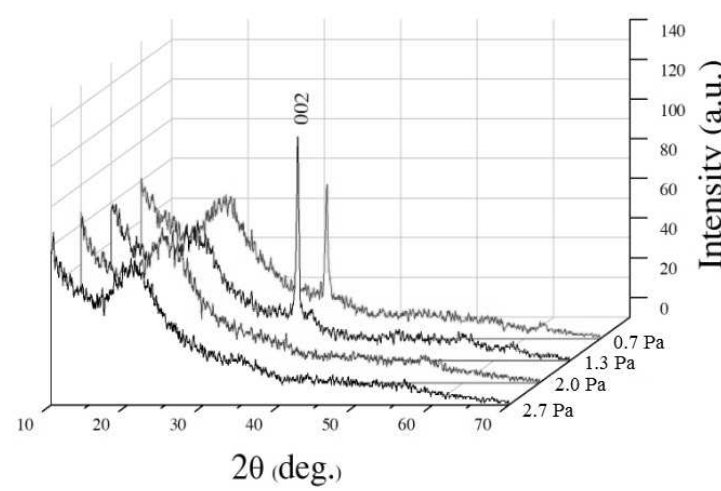

(a)

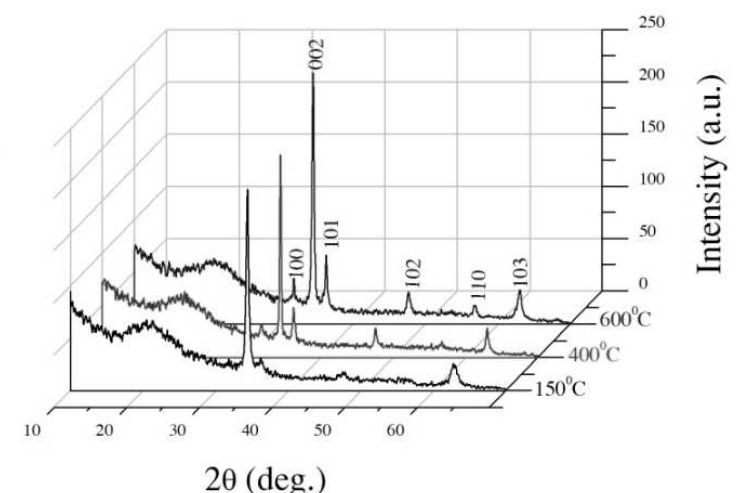

(b)

Fig. 5. The XRD patterns of the (a) AZO-1 films and (b) AZO-2 films

Fig. 5(a) shows the XRD patterns of the AZO-1 films. It is clear that the films grown at lower oxygen pressure (i.e. 0.7 and $1.3 \mathrm{~Pa}$ ) exhibit a wurzite structure which has a highly preference for the (002) orientation whereas the films gown at higher oxygen pressure (i.e. 2.0 and $2.7 \mathrm{~Pa}$ ) exhibit an amorphous structure. The highest intensity of (002) peaks for the film grown at $1.3 \mathrm{~Pa}$ indicates that this pressure is the most suitable. The degradation of the crystallinity at high oxygen pressure has also been observed by S. M. Park et al. in growth of AZO films by using PLD [15] and has been attributed to the excess oxygen that might induce defects in the films. P. Zhan et al. have also found that the oxygen pressure of $1.4 \mathrm{~Pa}$ is the most favorable value for obtaining the best crystallinity for the $\mathrm{ZnO}$ films grown by PED [9]. In our case, the effect of oxygen pressure seems to be stronger and more obvious because the films were grown at room temperature, so that the influence of temperature has been eliminated. The fact that oxygen pressure has an optimal value originates from the requirement of the average energy per deposited atom which should be about 10-20 eV. This energy in one hand is strong enough to complete the disruption of the columnar morphology of the growing film but in other hand do not damage the surface. It is well-known that in PED and PLD technique, with the presence 
of background gases during ablation, the species arriving at substrate looses their average velocity as they undergo through scattering, thermalization and deceleration.

Fig. 5(b) shows the XRD patterns of the AZO-2 films. First of all, we can see that all films exhibit a wurzite structure with a highly preference for the c-axis orientation perpendicular to the substrate surface. The crystallinity evaluated from the intensity and full width at half-maximum of the (002) peak improves with increasing substrate temperature up to $400^{\circ} \mathrm{C}$. Further increasing the substrate temperature leads to a slightly degradation in crystalinity. The grain size estimated from Scherrer equation is about 30 $\mathrm{nm}$ for the best film, i.e. the one deposited at $400^{\circ} \mathrm{C}$. Hirata et al. [16], and Zhan et al. [9] have reported the similar effect of substrate temperature on the crystalinity of the $\mathrm{ZnO}$ films grown by PLD and PED. P. Zhan attributed the promotion of the (002) peak to the increase of adatom mobility as increasing substrate temperature. P. Zhan also explained the degradation of (002) peak at high temperature by structure zone model proposed by Thormton [17]. According to this model, the films deposited at high temperature $\left(>320^{\circ} \mathrm{C}\right.$ for his case) have zone three structures which contain much more randomly oriented grains formed by secondary nucleation and recrystallization.

The electrical resistivity measured on the AZO-1 films is very high. However, it is still possible to realize that the resistivity is lower for the films deposited at lower oxygen pressure. The substrate temperature dependence of electrical resistivity of the AZO-2 films was presented in Table 1. As can be seen from this table, the resistivity decreases dramatically with increasing the substrate temperature up to $400^{\circ} \mathrm{C}$, and then increases slightly again. Park et al. [9] have observed a similar phenomenon on undoped ZnO films grown by PLD and attributed the decrease of resistivity to the increase of both carrier concentration and carrier mobility. The slight increase in resistivity of the films grown at high temperature was explained by the contamination of $\mathrm{C}$ from quartz substrate. Hirata et al. [16] reported that resistivity of Ga-doped $\mathrm{ZnO}$ films deposited by PLD decreases with increasing deposited temperature up to $300^{\circ} \mathrm{C}$ which is the highest investigated temperature. Since the facts that there is a close relation between the crystallinity and conductivity and that our films are $\mathrm{ZnO}$ doped with $\mathrm{Al}$, we suggest that the enhancement of conductivity is mainly due to the increase of number of $\mathrm{Al}$ atoms really activated in matrix oxide to produce extra electrons in the band. The resistivity of $3.4 \times 10^{-5} \Omega \times \mathrm{m}$ obtained at the optimal temperature is still quite high for requirement of TCO films. An additional process for improving electrical resistivity is necessary and will be studied in next future.

Table 1. The substrate temperature dependence of electrical resistivity of the AZO-2 films

\begin{tabular}{|c|r|}
\hline Substarte temperature & Electrical resistivity \\
\hline $25^{\circ} \mathrm{C}$ & $\sim 10^{-2} \Omega \times \mathrm{m}$ \\
\hline $150^{\circ} \mathrm{C}$ & $5 \times 10^{-3} \Omega \times \mathrm{m}$ \\
\hline $400^{\circ} \mathrm{C}$ & $3.4 \times 10^{-5} \Omega \times \mathrm{m}$ \\
\hline $600^{\circ} \mathrm{C}$ & $8 \times 10^{-5} \Omega \times \mathrm{m}$ \\
\hline
\end{tabular}

The optical transmittance of the films in both AZO-1 and AZO-2 series are very high (more than $80 \%$ ) in the range of $350-900 \mathrm{~nm}$. It is worth to note that there is a relation 
between the crystallinity and the transmittance, e.g. the highest value of transmittance $(\sim 90 \%)$ has been obtained for the film which has the best crystallinity. This value meets the application requirement of transmittance exceeding $80 \%$. The relation between the crystallinity and the optical property can be seen more clearly from the absorption spectra. The absorption spectra of AZO-1 and AZO-2 films are shown in Fig. 6(a) and 6(b), respectively. The absorption spectra of AZO-1 films have a tail in the transparent zone while the absorption spectra of all AZO-2 films have a sharp absorption edge. The value of band gap about $3.2 \mathrm{eV}$ deduced from absorption spectra is somewhat lower than the value of $3.37 \mathrm{eV}$ measured on pure and bulk $\mathrm{ZnO}$ materials [18].

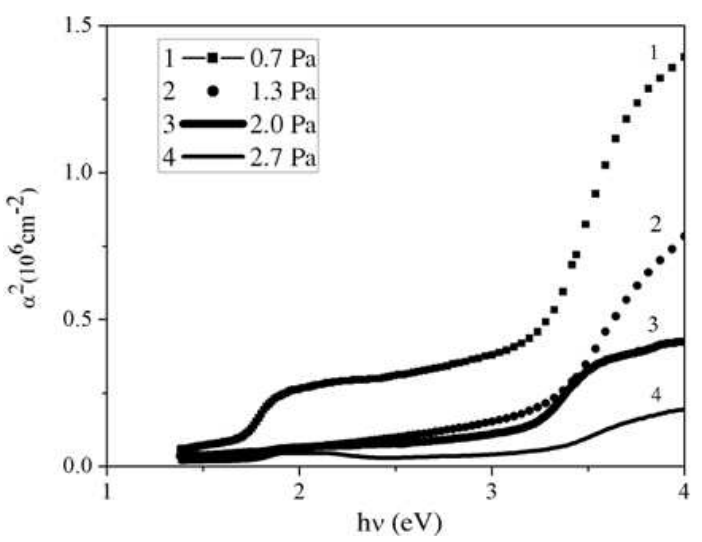

(a)

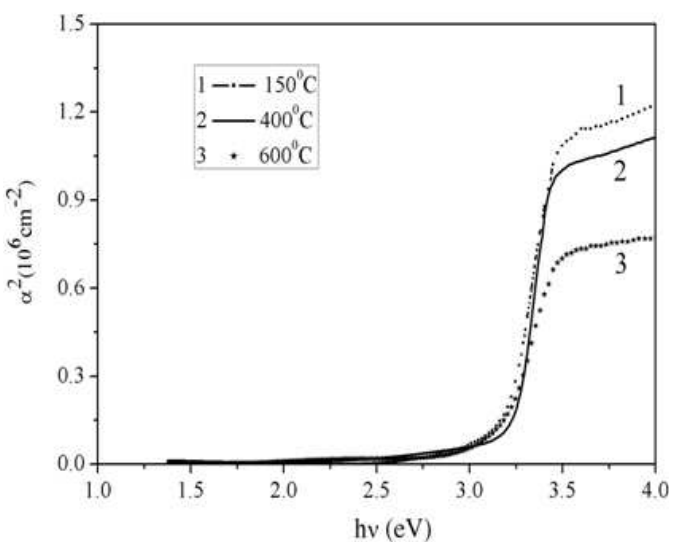

(b)

Fig. 6. The square of the absorption coefficient versus the photon energy curves for the (a) AZO-1 and (b) AZO-2 films

\section{CONCLUSION}

By using a PED equipment that has been set-up at Hanoi University of Science the transparent conducting $\mathrm{ZnO}$ and $\mathrm{Cu}(\mathrm{InGa}) \mathrm{Se}_{2}$ absorber films have been done. Several issuers concerning the optimal growth conditions for getting high quality films have been shown. For $\mathrm{Cu}(\mathrm{InGa}) \mathrm{Se}_{2}$, the best film was obtained at the discharge voltage of $12 \mathrm{kV}$ and substrate temperature of $400^{\circ} \mathrm{C}$, while for $\mathrm{ZnO}$, the best film was grown at the oxygen pressure of $1.3 \mathrm{~Pa}$ and at $400^{\circ} \mathrm{C}$.

\section{ACKNOWLEDGEMENTS}

This work was supported by the Vietnam National Foundation for Science and Technology Development (NAFOSTED) in the period 2010-2011 (Project Code 103.02.59.09).

\section{REFERENCES}

[1] G. Muller, M. Konijnenberg, G. Krafft, and C. Schultheiss, in Science and Technology of Thin Film, edited by F. C. Matacotta and G. Ottaviani (World Scientific, Singapore, 1995), pp. 89-119.

[2] S. D. Kovaleski, R. M. Gilgenbach, L. K. Ang, and Y. Y. Lau, J. Appl. Phys. 86 (1999) 7129. 
[3] R. Stark, J. Christiansen, K. Frank, F. Mücke, and M. Stetter, IEEE Trans. Plasma Sci. 23, (1995) 258.

[4] X. L. Jiang and N. Xu, J. Appl. Phys. 66, (1989) 5594.

[5] S. D. Kovaleski, R. M. Gilgenbach, L. K. Ang, and Y. Y. Lau, Appl. Phys. Lett. 73 (1998) 2576.

[6] R. Stark, J. Christiansen, K. Frank, F. Mucke, and M. Stetter, IEEE Trans. Plasma Sci. 23 (1995) 258.

[7] H. L. Porter, C. Mion, A. L. Cai, X. Zhang, J. F. Muth, Material Science and Engineering B119 (2005) 210.

[8] M. Nistor, N. B Mandache and J. Perriere, J. Phys. D: Appl. Phys. 41 (2008) 165205.

[9] P. Zhan, Z. Li, and Z. Zhang, Materials Transactions 52(9) (2011) 1764.

[10] G. Venkata Rao, G. Hema Chandra, P. Sreedhara Reddy, S. Uthanna, J. Optoelectron. Adv. Mater. 4 (2) (2002) 387.

[11] M. Andriesh, V. I. Verlan, L. A. Malahova, Journal of Optoelectronics and Advanced Materials 5(4) (2003) 817.

[12] K. K. Jain and P. K. Sharma, Appl. Phys. Lett. 62 (1993) 1466.

[13] M. Strikovski and K.S. Harshavardhan, Appl. Phys. Lett. 82 (2003) 853.

[14] M. Marudachalam, R. W. Birkmire, H. Hichri, J. Appl. Phys. 82 (1997) 2896.

[15] S. M. Park, T. Ikegami, K. Ebihara, P. K. Shin, Applied Surface Science 253 (2006) 1522.

[16] G. A. Hirata, J. Mc Kitrick, J. Siqueiros, O. A. Lopez, T. Cheeks, O. Contreras and J. Y. Yi, J. Vac. Sci. Technol. A14(3) (1996) 791.

[17] J. A. Thornton, Rev. Mater. Sci. 7 (1977) 239.

[18] D. G. Thomas, J. Phys. Chem. Solids 15 (1960) 86. 